\title{
Comprehensive English Teaching from the Angle of English Linguistics Cuilan E
}

\author{
Tianshi College Tianjin China 301700 College English Excellent course JP20140002
}

\author{
Keywords: English linguistics; Comprehensive English
}

\begin{abstract}
Language is the most important of human communication bridge, English as a region the most widely used language in the world, is the rapid development of economic globalization. Our country should strengthen with the rest of the world political, economic and cultural exchanges must first conquer English, make full use of the characteristics of English is the world common language, increase the speed of the development in China in the globalization process. In recent years, become a popular major colleges and universities, English majors comprehensive English is a basic course for English majors, in order to improve the students' comprehensive English, cultivate good English professional talents, colleges and universities should be from all aspects, strengthen their comprehensive English teaching. In this paper, we based on the analysis of the English language, to discuss how to optimize the comprehensive English teaching.

Comprehensive English is the most Basic English majors at universities of a course; it will be closely linked to the theoretical knowledge and practical skills, to fully develop the students' language basic theoretical knowledge and practical language application ability. English language is another important course for English majors, through teaching of basic theory of linguistics, make the students master the analysis of the English language ability, to lay a solid foundation for improving the comprehensive English level, to help students in the future life and work, strengthen English comprehensive application ability more quickly. Therefore, for comprehensive English teaching, English linguistics is the chain of connection of English teaching, the accurate application of student's oral English pronunciation, writing plays an important role.
\end{abstract}

\section{English Teaching in Our Country}

In recent years, more and more importance to English teaching in China, a lot of primary school to bring forward the opening time of the English class, the students first time getting up earlier and earlier, and exposure to English in a variety of English to open in early education class, and are designed to help students to advance a dozen good English learning in our country, the basis of correct English pronunciation accuracy. However, due to the intelligence, understanding ability, and learning ability and so on factors, the effectiveness of English teaching is still in college to maximize.

Any course of study, the final is for the practical application, English is one of the representatives of the course. For now, however, English teaching in China still adopts the traditional teaching mode of English classroom teaching, students can only rely on teachers of textbooks for the interpretation of knowledge, and not enough teachers due to reserve knowledge, and the development of knowledge update not in time, cause has certain restrictions on the student's English professor. ${ }^{[1]}$ At the same time, the traditional teaching mode for the cultivation of students' autonomous learning ability, lead to students in the process of English learning, unable to involve a wider range of knowledge, can't well apply the theoretical knowledge into real life and work. This for applied strong professional English is very big.

Along with our country and the world's political, economic and cultural exchanges between the increasingly close, the English teaching of our country are also constantly improving policy system. Universities begin to realize that English language to improve students' integrated English level have a vital role, so set up English linguistics as compulsory course for English majors. At the same time make full use of the English language in phonetics, grammar, semantics, language and culture in detail, such as knowledge to the students' English language sense and the inertia of culture, help to improve students' comprehensive English level. 


\section{The Importance of English Linguistics to Comprehensive English Teaching}

We often say "read a book hundreds of times its righteousness from now", is not to say that let the students to rote learning of theoretical knowledge, but to guide students to learn knowledge. In the process of English teaching, teachers should fully develop the students' ability of autonomous learning, after remember the classroom teaching theory knowledge, can be flexible to put theoretical knowledge into practical application ability. Such as a certain time at a certain situations, students met a realistic scenario, before you can transfer the learning theory knowledge, with practice, is transformed into practical ability. This transformation not only help students to improve the comprehensive level of English, also increased the students' interest in learning to accept ability and learning.

In the comprehensive English teaching, to complete the above goals, without the guidance of the English language. College English teaching aims to cultivate a large number of outstanding, and has a strong ability to apply knowledge of English professionals. English linguistics is a according to the historical development of English, the word structure, semantic understanding, to study the function of the meaning of the English language discipline. $\left.{ }^{[2}\right]$ Through the guidance of scientific English linguistics, students can better the origin and connotation of English and understand English in the historical evolution and development of cultural and social development, so as to improve the enthusiasm of students in English learning, can ensure that students in life and work, make full use of what they have learned theoretical knowledge to solve the corresponding problems. Give full play to the active function in the course of comprehensive English teaching in English linguistics, will be able to make the development of comprehensive English teaching more systematic and scientific develop top talent to adapt to the development of globalization, to ensure our advantages in the development of globalization.

\section{The Application of English Linguistics in Comprehensive English Teaching}

In the process of comprehensive English teaching, English linguistics have a vital role, universities need to make full use of the advantages of the English language, to improve students' comprehensive English level, to the globalization of our country develop English practical talents.

Phonology and Phonemics. Phonology is the main research object phonetic system, is the language sounds of vowels, consonants and articulation are studied. Phonology is mainly to study the relations of the combination of sound, including the phoneme, syllable, tone, intonation, etc.

${ }^{[3]}$ Because our country is the exam-oriented education, in evaluation of comprehensive English level, in writing, and ability to solve the problem as the evaluation criteria, so most of the students in English writing and English skills to solve the problem is the strengths, in English listening and spoken English is very weak, and the English language's phonology and phonemics just to solve the problem.

Used in the teaching of integrated English, phonology and phonemics guide students to distinguish between vowels and consonants, and get the correct pronunciation of the pronunciation, the students of popular words pronunciation and special words to strengthen the contact and in a timely manner to correct. Also, pay attention to the students at the time of contact word pronunciation correct pronunciation word pronunciation, stress, the sentence and curt tone due to Chinese accent, help students to attach importance to the pronunciation of English words and sentences, ensure that every English major speaks perfect English accurately.

Morphological Study. Morphological study mainly is to study the structure and composition of English words. In the process of comprehensive English teaching, the word quantity too large and complex, remember the words is also the most difficult to conquer English major students, many students because of inability to grasp the composition of root and words, lead to remember the words slow and inefficient. Morphological study can let the student through the patchwork method, derivative method, methods of synthesis, catalysis; help the memory of the word. Such as the meaning of the "video" is the "video", the meaning of the "telephone" is a "phone", "videophone" semantics is "videophone. Students through the form of learning and mastery of the English word 
formation rules, can more quickly remember English words, and the more solid of the memory of English words, and improve the efficiency and quality of comprehensive English teaching.

Semantics. In the process of comprehensive English learning, we often come across a word has multiple meanings, and also in different sentence righteousness, this leads to a demerit words, we are still not clear in the reading comprehension to determine its exact meaning. And semantics is aimed at the situation, analysis, and put forward a variety of methods, help students to understand and to remember English words of semantics. Such as "independent" semantics is "autonomous, independent, nonpartisan", the phrase "financially independent" financial independence, can help students to deepen the understanding of "independent" and memory. Again, for example, "loyal" as an adjective semantic for "loyal", as a noun is "loyal subjects, faithful" mean, as a result, students can through the meaning of two related to memory, so that we can improve the speed of the memory of English words, also to the meaning of English words have more comprehensive understanding.

Other Law. Take apart law mainly aimed at the long difficult sentences, find out long difficult sentence grammar structure, instruct students to long difficult sentences for thorough analysis. Such as the complicated long difficult sentences "" Coming in a close second - and, wrongly mentioned as the most distant island - is its island, which lies 1260 miles east of on its neighbor, Pitcairn island, and 2300 miles west of South America." a word has 35 words, but also an inverted sentences, then we have to tear down first two dashes between sentences, find out the main parts and the horse into the correct word order "its island is" Coming in a close second ", meaning "its island is the most remote island close second."; Then, we have to understand content between two dashes "often mistaken for the most remote island.", as well as the content of the attributive clause "it from the nearby islands of Pitcairn Island, 1260 miles to the east, from the 2300 miles to the west of South America. "After break up such a structure, the whole long difficult sentences and priorities, we can understand the meaning of the sentence to express quickly. Because English pay attention to the cohesion and coherence of the sentence, as a result, we just tell the whole structure of the sentence, to accurately understand the meaning of the main part, can quickly understand long difficult sentence meaning, which can not only help students master the reading comprehension, but also to students in English writing in the grammatical structure of a sentence.

Pragmatics. Pragmatics mainly through social and cultural background to study the rules of language and conversational implicature.We are learning English and practical application, often found in western countries in some Chinese habits, way of thinking there are big differences, such as name, Chinese believe that the pecking order, approaches are different, not only in terms of relative appellation division was very clear, in social activities, also pay great attention to form, to the higher level will bring, one of the most common is "XX manager" in the workplace, director of "XX", etc. Again, for example, Chinese people have praised, he always adhering to the humble attitude, will "lottery", "where" and other words hang in the mouth, while the westerners, in the face of the compliment is accepted, no matter seen in the film and television play, or in daily life activities come into contact with, the most often hear is "Thank you". These differences from Chinese and western culture and the different social background, so in the teaching of integrated English, English linguistics, pragmatics can help students better understand the English language environment and cultural background, habits and thinking, so as to enable students to master English practical skills, can have more advantages to the development of China's globalization . ${ }^{[4]}$

Anyhow, comprehensive English teaching is a major teaching for English majors, it starts from the basic knowledge and practical application of students, cultivate a solid basic knowledge of English and English application abilities of the flexible top talent. English language in the application of comprehensive English teaching, have the effect of the adhesive, will all aspects of the comprehensive English teaching together, and in the process of students' comprehensive English learning, leak fill a vacancy, improving students' comprehensive English knowledge theory system, make overall improve the students' integrated English level, for China's political, economic and cultural globalization in the future development, the continuous conveying top combat type personnel. 


\section{References}

[1] Jiang Hui, countries based on the construction of a socialist education mode explore [J]. Journal of English linguistics 2014 (10) the contemporary education theory and practice.

[2] Xu Guyu Chen Jian, Liang Qionglin. Analysis from the perspective of English language comprehensive English teaching [J]. Journal of yantai vocational college. 2014 (6)

[3] Zhao Ying. From the perspective of English linguistics analysis [J]. Journal of comprehensive English teaching education teaching BBS. 2015 (7)

[4] Shu-kang li, li ke. The look the present situation of the English language teaching and English language teaching [J]. Crazy English teachers. 2008 (02) 